\title{
Expansión y ruptura del orden liberal en Bolivia, 1900-1932
}

Ferran Gallego

Universidad Autónoma de Barcelona

El propósito de este trabajo es ofrecer una valoración general de la evolución política y económica de Bolivia en los inicios del siglo XX, momento crucial para el asentamiento de la nueva élite minera del estaño, para la normalización de las instituciones políticas y para la expansión de la economía monoexportadora. Tal visión puede acercarnos a una etapa poco conocida en la evolución de la república andina, señalando cómo la aparente estabilidad de un modelo de crecimiento basado en la monoexportación contenía factores de desequilibrio que el estallido de la Gran Depresión y la guerra del Chaco no harían más que agravar.

Si hay un lugar común en la historia de Bolivia, sin duda es el que identifica el siglo XX con el estaño, antes de que la crisis de esta producción orientara la reputación del país hacia el cultivo de la coca. Sea para condenarlo como "Metal del diablo" o para construir confortables modelos de monoproducción, el "problema boliviano" se piensa, desde la novela hasta la estadística, como una referencia del mineral. Tal reduccionismo nos acerca, por tanto, no sólo al carácter del crecimiento económico, sino también a una conciencia colectiva obsesivamente inspirada en la riqueza y expoliación del subsuelo.

Naturalmente, se trata de observar hasta qué punto la imagen encuentra su correspondencia en la realidad. Siendo muy escrupulosos, podríamos añadir el caucho primero, el petróleo después y, en fases muy concretas, el cobre o el wolframio. Mas aunque ello aporte un sano ejercicio de desmitificación, la contundencia de las cifras desalienta las matizaciones. Y hay que empezar por ellas. A falta de un indicador más elocuente - las oscilaciones del producto interior, por ejemplo-, el incremento del comercio exterior puede ofrecernos una aproximación a los índices generales de crecimiento.

Las exportaciones bolivianas se multiplican por 4,5 entre 1896 y 1930. Las importaciones, por 5,2. Globalmente, el comercio exterior pasó de algo menos de 40 millones de bolivianos en el quinquenio 1896-1900 a más de 187 millones en el quinquenio $1926-1930 .{ }^{1}$ La responsabilidad del estaño en

1 Comisión Económica Para América Latina (CEPAL): El desarrollo económico de Bolivia. México, 1958, pág. 7. 
el alza del comercio exterior es decisiva: de representar el $41 \%$ de las exportaciones a comienzo de siglo, pasa a un 73,8\% en 1926-1930. La procedencia de las exportaciones por Departamento nos indica el peso de la minería: en 1918, el 64,22\% corresponde a Potosí y el 17,43\% a Oruro. Cochabamba, Santa Cruz y Chuquisaca no alcanzan el $1 \%$. Y minería, en aquel momento, significaba estaño, como nos lo indica el hecho de que la plata haya descendido a niveles patéticos. En ese mismo año, representa el $1,83 \%$ y el $1,75 \%$ para sulfuros y mineral de plata respectivamente. ${ }^{2}$

El auge del estaño en la economía boliviana se relaciona con tres variables: el descenso en el valor y la producción argentífera, el aumento de la demanda mundial, y su pureza y relativamente fácil explotación en las primeras décadas. En el último punto hay que anotar que los filones de estaño se encontraban generalmente asociados a los de la plata, y el mineral había formado parte del material de desmonte acumulado en los momentos de mayor producción argentífera. La pureza del mineral permitiría su explotación rentable a pesar de los costes de producción, mucho más altos que los orientales. Finalmente, la generosa política fiscal actuaría como compensación de los altos costos y complemento de la pureza del mineral para consolidar la actividad estañera como la industria punta de la economía boliviana. ${ }^{3}$

El desarrollo de la producción mundial de estaño sería constante hasta la depresión de los años 30, cuando el exceso de stocks obligaría a llegar a acuerdos para controlar la oferta. ${ }^{4}$ La producción mundial se multiplicó por 2,07 entre 1900 y 1930, mientras que la boliviana lo hizo por 4,18 en el mismo período. La participación de Bolivia en la oferta total pasó del $10,7 \%$ al 21,6\%..$^{5}$ La demanda del estaño, reforzada por sus nuevos usos industriales, se reflejó en la cotización internacional. Tomando el precio de 1899 como índice, en 1905 se pasa a 127, en 1910 a 138 y en 1918 a $293 .{ }^{6}$

2 Schurz, W. L.: Bolivia. A Commercial and Industrial Handbook. Washington, 1921, páginas 222-223.

3 Para una apreciación de los costos de producción de estaño, ver Peñaloza, L.: Historia económica de Bolivia, vol. II, La Paz, 1954, págs. 213 y ss.

4 Sobre la coordinación internacional del estaño ver el libro clásico de Knorr, K. E.: Tin under control. Stanford, 1945. Para su aplicación y efectos en Bolivia, véanse los trabajos de B. Hallowell "Administration of Tin Control in Bolivia, 1931-1939", Inter American Economic Affairs, Washington, 1947, págs. 3-24; "Tin Control and Exchange Depreciation in Bolivia, 1931-1939", Inter American Economic Affairs, Washington, 1951, págs. 71-84; así como el más reciente de J. Hillman, "Bolivia and the International Tin Cartel" Journal of Latin American Studies, Cambridge, 1988, págs. 83-110.

5 CEPAL: El desarrollo..., pág. 8.

6 Peñaloza, L.: Historia... vol. II, pág. 209. 
En esos mismos años, la exportación de estaño en Bolivia siguió un ritmo más acelerado: $1899=100,1905=290,1910=415,1918=525 .^{7}$ Ningún otro producto llegó a adquirir la importancia del estaño en los primeros treinta años del siglo. La plata, base de la formación del orden liberal oligárquico junto con el latifundismo, exportaba tan sólo 8 millones de bolivianos en 1908 - cuatro veces menos que el estaño- y 7 millones en 1918 - 18 veces menos. A pesar de la breve recuperación de 1919-1922, volvería al punto de partida antes de la depresión de los años $30 .{ }^{8}$ Perdidos territorios fundamentales por la guerra del Acre, establecida la competencia asiática, el caucho pasaría a representar un 6,04 de las exportaciones bolivianas frente al 22,89 de $1911 .{ }^{9}$ El cobre, el wolframio y el antimonio, se beneficiaron solamente de situaciones excepcionales, como la demanda en tiempos de la Gran Guerra. La exportación de wolframio se multiplicó por 10 y la de antimonio por 442, al tiempo que los precios se disparaban. El cobre pasó de las 8.000 toneladas de 1914 a las 37.000 de $1917 .{ }^{10}$ Pero el cambio de circunstancias en 1918 devolvió el cuadro que se había venido diseñando desde comienzos de siglo.

\section{Régimen fiscal y déficit de Hacienda}

El Partido Liberal gobernó la república en los años de mayor florecimiento económico. Su programa se había referido obstinadamente al progreso del país, lo cual significaba optar por el despegue de la minería que, habiendo sido el fundamento tradicional del desarrollo altoperuano, se presentaba ahora, en la época del estaño, con perspectivas más alentadoras que en la de la plata. El aprovechamiento de dicha potencialidad tenía fórmulas distintas de realización, y el papel del Estado era decisivo teniendo en cuenta sus recursos para estimular por la vía fiscal la fundición en lugar de la exportación en bruto, así como de redistribuir el beneficio por medio de las inversiones públicas, propiciando la diversificación e integración del mercado nacional. El liberalismo eligió otro camino: su política fiscal ten-

7 Schurz, W.: Bolivia..., pág. 109.

8 Ibídem, pág. 112. Otero, Gustavo Adolfo: Notas sobre el comercio exterior boliviano. Barcelona, 1929, pág. 88.

9 Sin embargo, el valor de las exportaciones se mantendría más constante, aunque el crecimiento de la producción del estaño haría bajar su valor relativo. En 1911, el valor del caucho exportado era de 18.921.000 bolivianos, mientras que en 1918 había bajado a 11.308.000. Schurz, W.: Bolivia..., págs. 176-177.

10 MacQueen, Ch.: Bolivian Public Finances, Washington, 1925, págs. 9-10. 
dió - con muchas oscilaciones - a gravar lo menos posible la producción y comercialización del estaño. Sus ingresos se emplearon en la construcción de una red ferroviaria que debía permitir el contacto de la mina con una demanda exterior en expansión y la entrada de manufacturas y alimentos en el marco altiplánico. Cuando los recursos fiscales resultaron insuficientes, cuando se hubo agotado el beneficio obtenido con las indemnizaciones del Acre y del Litoral, se recurrió a una política de empréstitos que llevaría el país a la quiebra en la depresión de los años 30. Veamos más de cerca estos factores.

En los últimos años del siglo XIX, el impuesto sobre exportación de estaño fundido y "reducido" - barra y barrilla, respectivamente- había crecido en un $100 \%$, situándose en un boliviano por quintal — de $46 \mathrm{Kg}$ de barrilla y 1,6 bolivianos por quintal de barra, con lo que se favorecía la exportación del estaño no fundido. A esta medida vinieron a sumarse solamente, antes de la Gran Guerra, el llamado impuesto de estadística y, sobre todo, la modificación introducida en noviembre de 1912, que establecía una escala de impuestos de acuerdo con la cotización londinense: ${ }^{11}$ en 1914 se fijaba un impuesto del $2 \%$ sobre dividendos; en 1919 se estableció un impuesto del $8 \%$ sobre utilidades mineras superiores a 20.000 bolivianos, aunque con un descuento del $25 \%$ sobre los derechos de exportación, lo cual podía llegar a neutralizar totalmente el efecto del impuesto original. La última medida del gobierno liberal fue tomada por Gutiérrez Guerra en febrero de 1920, decretando una escala impositiva calculada sobre el porcentaje de beneficios, tras descontar un $10 \%$ de las utilidades líquidas: la tasa oscilaba entre el 8 y el $30 \% .{ }^{12}$ Lo que resulta especialmente significativo es contrastar variables como: ingresos fiscales obtenidos por la comercialización del estaño, el valor total de sus exportaciones y los ingresos globales del Estado. Entre 1900 y 1920, los ingresos en concepto de tasas a la exportación de estaño supusieron un porcentaje comprendido entre el 2 y el $6 \%$ del valor de los embarques. En el período 1904-1920, el estaño representó un mínimo del $42,93 \%$ y un máximo del $72,32 \%$ del valor total de las exportaciones, con un promedio para el conjunto de los 17 años del 60,37\%. En las dos primeras décadas del siglo, los derechos sobre exportación de estaño oscilaron entre un mínimo del 3,99 y un máximo del 25,7\% del total de los ingresos estatales, con un promedio del $12,98 . .^{13}$

11 Chávez Ortiz, Ñ.: El signo del estaño. La Paz, 1961, págs. 120 y ss.

12 Peñaloza, L.: Historia..., vol. II, pág. 228.

13 Ibidem, págs. 220-227. 
Las rentas gubernamentales presentaron una tendencia prácticamente ininterrumpida al crecimiento, pasándose de los 6 millones de bolivianos de 1901 a los 30 millones en 1920. Salvo en coyunturas depresivas muy localizadas, el Estado dispuso siempre de ingresos superiores a los del año anterior. ${ }^{14}$ Un aumento tan sustancial de las rentas públicas no fue suficiente, sin embargo, para equilibrar el presupuesto. Entre 1901 y 1920, sólo en dos ocasiones - 1912 y 1918 - existe superávit. Mientras el valor de las exportaciones de estaño se multiplicaba por 6,6 entre 1904 y 1920, su contribución en los ingresos públicos lo hacía por 13,2: de representar el $6,85 \%$ de los fondos estatales había pasado al 20,36\%. Esta aparente colaboración de la minería merece ser matizada: dado que el porcentaje pagado por los exportadores sobre sus beneficios prácticamente no sufre variación en todo el periodo, el aumento de los ingresos procedentes de la minería no se debe a una mayor dureza fiscal, sino al espectacular crecimiento de la demanda exterior.

\section{La deuda pública}

Desde la guerra del Pacífico hasta 1908, el permanente déficit del presupuesto fue financiado por la deuda interna. A partir de ese momento, aparece una tendencia que se irá confirmando hasta la quiebra de los años 30: la búsqueda de recursos en el exterior. El peso de la deuda interna no es despreciable, pero se encuentra siempre por debajo de la externa. ${ }^{15}$ Una vez mostrada la insuficiencia del mercado de capitales boliviano, se recurrirá a empréstitos extranjeros antes que a una reconversión de la política tributaria, lo cual tenía plena coherencia con el proteccionismo liberal sobre el sector responsable del progreso económico.

Entre 1908 y 1920 se contrataron los siguientes empréstitos externos: 1.') Con la Banca Morgan, de Nueva York, 500.000 libras esterlinas, al 6\% de interés, destinado en principio a la financiación de la entrada de Bolivia en el patrón oro. Fue necesario un empréstito posterior, en 1922, para redimirlo. 2. ${ }^{\circ}$ ) Con el Crédit Mobilier, 1.500 .000 libras esterlinas, al 5\% de interés, destinado a financiar parte del Banco de la Nación Boliviana. 3. $\left.{ }^{\circ}\right)$ También con el Crédit Mobilier, 1.000 .000 libras esterlinas, al 5\% de

14 CEPAL: El desarrollo..., pág. 11.

15 Ch. McQueen (Bolivian..., pág. 39) calcula el importe de la deuda total en 1923 en 102.444.117 bolivianos, correspondiendo 72.867 .110 a la exterior. 
interés, destinado a la construcción del ferrocarril Atocha-La Quiaca. $4 .^{\circ}$ ) Con el Chandler Bank, 2.400.000 dólares, al 6\% de interés, destinado a la construcción del ferrocarril La Paz-Yungas. 5..$^{\circ}$ ) Con la Ullen Contrasting Co., 2.253.000 dólares, al 6\% de interés, para obras de saneamiento de Cochabamba y La Paz. En vísperas de la caída del gobierno liberal, la deuda externa acumulada equivalía a 40.990 .731 bolivianos, sobre una deuda total de 70.388.083. Téngase en cuenta que los ingresos totales del Estado en 1919 habían sido 24.977 .000 bolivianos y que los créditos pedidos en aquellos años se acercaban o incluso superaban los ingresos gubernamentales presupuestados. A dichos empréstitos deberían añadirse, por otra parte, la garantía estatal de los bonos emitidos por la red Speyer de ferrocarriles en 1906, que en primera hipoteca ascendían a 3,75 millones de libras esterlinas y en segunda a 2,5 millones, así como la garantía de los Bonos Erlanger, destinados a la construcción viaria en Cochabamba, por valor de 300.000 libras. En ambos casos, dicha garantía estatal se convirtió, por la insolvencia de la empresa, en obligación del gobierno a hacer frente al pago de los intereses de los bonos. Como resultado de este proceso, los presupuestos de 1915-1920 situaban la atención de la deuda en primer lugar, acaparando una tercera parte de los gastos. ${ }^{16}$

\section{Inversión Pública: los ferrocarriles}

Signo clásico del desarrollo económico, los liberales presentaron siempre el ferrocarril como su obra imperecedera de gobierno. Indudablemente, los primeros veinte años del siglo vieron la conexión de los grandes centros urbanos - salvo Sucre y Santa Cruz- y la vinculación del Altiplano con los puertos del litoral chileno, completando la orientación que ya se había dado al tejido viario por parte de los conservadores. M.A. Marsh, basándose en la Memoria del Ministerio de Fomento y Comunicaciones correspondiente a 1925, señala la existencia de una extensión total de $2.100 \mathrm{kms}$., con un coste aproximado de 16.260.000 libras esterlinas. ${ }^{17} \mathrm{El}$ tendido ferroviario enlazaba prácticamente todo el Altiplano y parte de los Valles, desde el Titicaca hasta Potosí, orientándose hacia la costa chilena por el viejo tramo Antofagasta-Oruro o por Arica-La Paz. La

16 CEPAL: El desarrollo..., págs. 11-12; Peñaloza, L.: Historia..., págs. 426 y ss.; Marsh, M. A.: Nuestros banqueros en Bolivia, Madrid, 1930, págs. 301-302; McQueen, Ch.: Bolivian..., pág. 35. 
vinculación con Oriente había quedado congelada con el fracaso del ferrocarril La Paz-Beni, manteniéndose así el aislamiento de Santa Cruz, Colonias y Beni. Otro factor importante es la escasa dimensión de la propiedad estatal frente a las concesiones a largo plazo o a perpetuidad en favor de la Bolivian Railway Co., o la Antofagasta and Bolivia Railway Co. Únicamente 362 kilómetros aparecen clasificados como propiedad directa del Estado. Por otro lado, su diseño no iba acompañado de un horizonte de desarrollo que permitiera la articulación de las distintas zonas del país en un proceso de crecimiento integrado. Que esto no es una afirmación en el vacío nos lo corrobora un observador contemporáneo, al indicar que en 1918 las importaciones de alimentos, licores y animales vivos suponen un $31,42 \%$, y las de productos manufacturados un 46,37. ${ }^{18}$ Y Silvia Rivera apunta la destrucción de una expansión mercantil de las comunidades altiplánicas por la competencia foránea facilitada por el ferrocarril. ${ }^{19}$

Indicativo de las fórmulas financieras utilizadas para la construcción del ferrocarril es el contrato firmado con los Bancos Speyer and Co. y el National City Bank, en mayo de 1906. En síntesis, tales organismos se comprometían a promover una empresa - Bolivian Railway Companycon capacidad para la emisión de bonos de primera hipoteca por valor de 3.750 .000 libras y de segunda por valor de 2.500 .000 , con vencimiento en 1927 y 1932 respectivamente. El gobierno garantizaba los intereses de las obligaciones de primera hipoteca y se obligaba a la compra de los bonos de segunda hipoteca, para lo cual empleó los recursos adquiridos con los tratados de paz con Chile y Brasil. Mientras el Estado se veía forzado a adquirir los bonos de segunda hipoteca a la par, los banqueros tomarían los de primera hipoteca depositando únicamente tres millones de libras. La construcción de la red se basó sobre los más de dos millones de libras colocados en depósito bancario por el gobierno para garantizar la primera hipoteca. En el momento de liquidación del contrato, se calculó la inversión real en casi 7 millones de libras esterlinas, de las cuales 4.647.581 correspondían al Estado, en concepto del capital depositado de antemano y en el del pago de intereses de primera hipoteca. ${ }^{20}$

De hecho, la orientación de los fondos públicos a la construcción viaria y la previa desviación de una parte considerable de los mismos al pago

\footnotetext{
17 Marsh, M. A.: Nuestros banqueros..., págs. 301-302.

18 Schurz, W.: Bolivia..., pág. 226.

19 Rivera, S.: "Rebelión e ideología. Luchas del campesinado aymara del altiplano boliviano, 1910-1920” Historia Boliviana, 1/1, Cochabamba, 1981, págs. 91-92.

20 Peñaloza, L.: Historia..., vol. II, págs. 353-379.
} 
de deuda van estrechamente relacionados, considerando que en la etapa liberal una parte sustanciosa del crédito fue empleada para amortizar las obligaciones adquiridas y pagar los intereses garantizados. Por ello no deja de ser un tanto caprichosa la cuantificación de W. Gómez d'Angelo, cuando sitúa el porcentaje de gastos del gobierno dedicados al desarrollo en cifras que oscilan entre el 20 y el $48 \% .^{21}$ La lectura de los presupuestos sólo nos ofrece una consideración semejante si incluimos los gastos de empréstitos y garantías de hipoteca dedicados a negocios con empresas concesionarias de la talla del contrato Speyer. En el presupuesto de 1918, por ejemplo, hallamos el siguiente reparto porcentual de recursos:

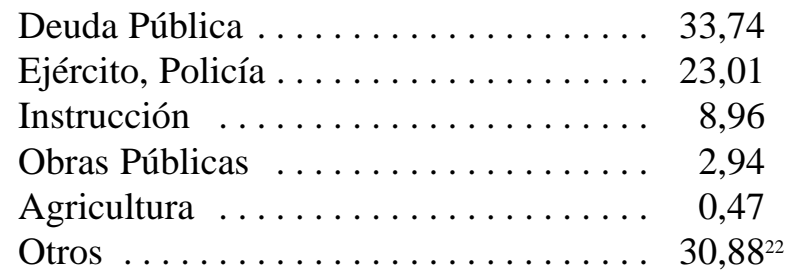

\section{La gestión política liberal}

El análisis del papel jugado por el Estado en la ordenación del crecimiento económico matiza la imagen de expansión sin fisuras que nos podría poner de manifiesto una simple lectura de la balanza comercial, impresionante por el volumen de las exportaciones y por el valor de la producción boliviana en el mercado mundial. Nos ayuda, por tanto, a enfocar la arritmia de una formación social aparentemente armónica y a entender las causas últimas, no tanto de la crisis de los años 30 como de la incapacidad para responder a ella desde la lógica del modelo diseñado en la fase liberal.

La llegada del Partido Liberal al poder supuso la expansión y modernización del proyecto oligárquico. Klein defiende la formación de un amplio tejido de políticos profesionales a los que recibe un aparato del Estado con mayores recursos que el del XIX. Un biógrafo de Siles comenta la casi exclusiva dedicación de las universidades bolivianas a la formación pág. 216.

21 Gómez d'Angelo, W.: La minería en el desarrollo económico de Bolivia. La Paz, 1978,

22 McQueen, Ch.: Bolivian..., págs. 34-36. El epígrafe "otros" se refiere a gastos del legislativo, justicia, asuntos exteriores, culto, colonización, etc. 
de abogados que intentan nutrir las filas de la función pública. Y Malloy ha señalado, como uno de los factores de creación de nuevas fuerzas políticas de carácter clientelar, la lucha por la ocupación de unos cargos públicos que escasean frente a la gran demanda de jóvenes leguleyos. ${ }^{23}$

El Partido Conservador, aun permitiendo la existencia legal de los liberales, había practicado una política exclusivista que acabaría volviéndose en contra suya: al identificarse con el periodo de expansión platera, hasta el punto de que algunos de sus presidentes serían empresarios del sector, el declive de la producción acompañaría a la única fuerza que había ostentado el poder desde 1880. Los liberales, cuya profesión de fe había sido la pureza del sufragio censitario, dirigirán la república con criterios bastante semejantes a los de sus antecesores. Aprovechando la estabilidad cedida por la expansión económica, aprovechando incluso un prestigio lentamente devaluado de "partido de izquierdas" — lo cual le concede hasta la dirección de las primeras sociedades obreras-, el Partido Liberal se convierte, de hecho, en partido único del país, con la disolución de los constitucionalistas conservadores y con la simple oposición de algunas facciones de notables, escindidas de la familia liberal - "puritanos" y "patiñistas", por ejemplo. Hasta el surgimiento de la Unión Republicana en 1914-1915, la figura de Ismael Montes, dos veces presidente de la República y hombre fuerte del Partido Liberal, regirá sin alternativa el ritmo institucional del país. Buena prueba de ello es la inexistencia de candidaturas de oposición en las elecciones presidenciales de 1908, 1909 y 1913, así como el penosísimo resultado alcanzado por "puritanos" y conservadores en 1904 y por republicanos en 1917, cuyo fracaso no cabe atribuir ni exclusiva ni principalmente a la manipulación del voto letrado.

El Partido Liberal inició su mandato renunciando a dos apoyos que le habían permitido, respectivamente, justificar y realizar su marcha al poder. Mientras el federalismo era rápidamente abandonado en el congreso de 1900, a pesar de haber sido el pretexto para iniciar la guerra civil de finales de siglo contra los conservadores, las promesas realizadas a los indígenas fueron olvidadas, llegándose a la ejecución de algunos cabecillas que habían colaborado en la rebelión..$^{24}$ Marta Irurozqui ha demostrado brillan-

23 Klein, H.: Parties and Political Change in Bolivia, 1880-1952. Cambridge, 1969; Carrasco, B.: Hernando Siles. La Paz, 1961, pág. 54; Malloy, J.: "Estudio de un movimiento popular nacionalista en América Latina”. Estudios Andinos, 1/1, Pittsburgh, 1970, págs. 57-91.

24 El mejor estudio sobre la participación indígena en la guerra federal es el de Condardo Morales, R.: Zárate el Temible Willka. La Paz, 1966. 
temente que la formación de la élite liberal paceña, que había cimentado su prestigio movilizador del campesinado en la promesa de reinstaurar la relación de reciprocidad con los indígenas, habría de basar su proyecto nacional en una estudiada exclusión de aymaras y quechuas, que ni siquiera hacía ascos a los discursos darwinistas. ${ }^{25}$ El proceso de sustitución de tierras indígenas por haciendas se aceleraría con la "normalización" de la vida política boliviana tras la guerra del Pacífico. George McCutchen McBride, en una descripción de la vida indígena del altiplano realizada en 1921, señala que las comunidades se hallan en los lugares de más difícil acceso, mientras las haciendas se encuentran "a lo largo de las principales carreteras", siendo de reciente creación y compuestas por tierras que "tiempo atrás fueron poseídas por los indígenas comunitarios". ${ }^{26}$

El primer presidente liberal, J.M. Pando, dedicó la mayor parte de su mandato al tercero de los grandes conflictos internacionales padecidos por Bolivia desde su independencia. Durante los años 80 y 90, el espacio de los ríos tributarios del Amazonas - Acre, Orton, Beni, Mamoré- se había convertido en una región codiciada por el incremento de la demanda mundial de caucho. Se trataba de una zona escasamente colonizada por la iniciativa pública boliviana, a pesar de que se habían planificado, en décadas anteriores, enlaces viarios que incluían proyectos de ferrocarriles y canales. Lo inhóspito del territorio hizo fracasar tales intentos, que quedaban en manos de algunos empresarios privados, singularmente la Casa Nicolás Suárez. La república ni siquiera estuvo en condiciones de preocuparse por establecer una aduana que controlara la salida de caucho hacia el Madeira. Brasil disponía así de ciertas ventajas sobre su vecino: una mayor velocidad en el engarce con el mercado exterior y una migración considerable de población brasileña hacia la región en conflicto. Cuando Pando se decidió a instalar una aduana en Puerto Alonso, estalló una revuelta que proclamó el Estado Independiente del Acre y hasta 1901 no fue posible aplastar la insurrección. La debilidad del Estado boliviano se demostró dramáticamente en los episodios sucesivos. Consciente de la escasez de sus recursos y de las dificultades para defender un territorio tan lejano, Pando trató de interesar a empresarios estadounidenses, confiando en que una concesión a su favor permitiría presionar a Brasil con mayor eficacia. La constitución

25 Irurozqui, M.: Poder y élite en Bolivia, 1880-1920. Tesis doctoral. Universidad Complutense, Madrid, 1992.

26 McBride, G. M.: The Agrarian Indian Communities of Highland Bolivia. New York, 1921. 
del Bolivian Syndicate en 1901 no hizo sino acelerar el estallido del conflicto con Brasil, de resultados catastróficos para Bolivia. Hubo que aceptar en 1903 el reajuste solicitado por el vencedor, que suponía la pérdida de 200.000 kilómetros cuadrados al precio de una indemnización de dos millones de libras esterlinas. ${ }^{27}$ De cualquier forma, los esfuerzos de la oposición por levantar el ánimo popular aprovechando el agravio resultaron estériles, dada la expansión económica que se abrió con la explotación del estaño en este mismo período.

\section{El surgimiento del Partido Republicano}

Fue precisamente el cambio en la orientación de la coyuntura económica lo que permitió la formación de una alternativa política al liberalismo montista, a lo que se añadió una serie de medidas de carácter financiero que alejaron a una parte de la alta burguesía boliviana del proyecto liberal. En efecto, en 1913-1914, los precios del caucho y del estaño sufrieron un súbito descenso, más perceptible por la expansión de la etapa 1908-1912. Mientras las exportaciones caían a un 60\% de su valor de 1913, las importaciones no recuperarían el valor de este año hasta el fin de la Gran Guerra. ${ }^{28}$ La caída de los ingresos estatales había de tener un peso decisivo en la capacidad de satisfacer a una clientela potencial creciente, ávida de puestos públicos, que se orientó a la búsqueda de una alternativa "revolucionaria". Además, Ismael Montes acabó de enojar a sectores pudientes al establecer el monopolio de la emisión para el Banco de la Nación Boliviana, acompañándolo de una restricción en la circulación monetaria que empujó a fuertes restricciones del crédito comercial. ${ }^{29}$

Daniel Salamanca, notable cochabambino, fue elegido para coordinar los esfuerzos opositores, que desembocaron en la creación del Partido Republicano en 1914. Carecemos de una monografía seria sobre el nuevo partido, pero los datos dispersos en la literatura de la época nos sugieren la gran diversidad de su base social, de la misma forma que su programa nos indica solamente una serie de lugares comunes, eludiendo entrar en

27 Fifer, V.: Bolivia. Territorio, situación y política desde 1825. Buenos Aires, 1976, páginas $150-213$.

28 Schurz, W.: Bolivia..., pág. 221.

29 Sobre la influencia de la reforma bancaria en la opinión opositora, ver Alvéstegui, D.: Salamanca. Su gravitación sobre el destino de Bolivia. La Paz, 1957, vol. I, pág. 300. 
detalles que puedan agredir la fragilidad del reciente organismo. El Partido Republicano tuvo, sin duda, la capacidad de reunir descontentos plurales, desde sectores populares a viejos cuadros conservadores desplazados por la hegemonía liberal. ${ }^{30}$ De hecho, el Partido Republicano trató de llegar a un acuerdo con los liberales que permitiera la alternancia en la presidencia y una seria participación en el legislativo, elementos fundamentales para un acuerdo de élites. La intransigencia liberal, sin embargo, forzó la radicalización del republicanismo, permitiendo que en el seno del mismo fuera adquiriendo fuerza aquel sector más dispuesto a una estrategia rupturista y más atento a ganarse la clientela popular urbana. El prestigioso abogado y profesor universitario Bautista Saavedra habría de encarnar dicha tendencia. ${ }^{31}$

\section{El gobierno de Bautista Saavedra}

El 12 de julio de 1920, con la participación de algunos regimientos y la abstención del resto, el presidente liberal Gutiérrez Guerra era obligado a abandonar el Palacio Quemado. Por primera vez en el siglo XX, Bolivia sufría un cambio de gobierno violento, con la sustitución del partido que había dirigido el país desde 1899. Sin embargo, un acontecimiento de tal envergadura ha dado lugar a escasísimas interpretaciones. ${ }^{32}$ La literatura escrita en la época o recordada por los protagonistas se reduce a meras descripciones de la conspiración. ${ }^{33}$ Más recientemente, Herbert Klein se ha preguntado el porqué del cambio, rebasando el terreno de la mera narración. ${ }^{34}$ Sus referencias a las tensiones internas del liberalismo pueden aclarar algunos aspectos del surgimiento del Partido Republicano, pero más interesante resulta la vinculación con la crisis económica de la posguerra, aun cuando tengo algunas discrepancias en su periodiza-

30 La presencia de sectores populares está señalada en Céspedes, A.: El dictador suicida. Santiago de Chile, 1956, pág. 41. D. Alvéstegui señala la complicidad de las clases populares y sectores de la oligarquía conservadora en su biografía de Salamanca, vol. II, pág. 115.

31 La mejor biografía del caudillo republicano es la de Gómez, E.: Bautista Saavedra, La Paz, 1975.

32 Entre las últimas, véase la de Irurozqui, M.: "Partidos políticos y golpe de estado en Bolivia. La política nacional-popular de Bautista Saavedra, 1921-1925.” Revista de Indias, vol. LIV, n. ${ }^{200}$, Madrid, enero-abril 1994, págs. 137-156.

33 Por ejemplo, D. Alvéstegui (Salamanca... vol. II, pág. 251), B. Carrasco (Siles..., págs. 126 y ss) y P. Díaz Machicao ( Historia de Bolivia, Saavedra. La Paz, 1954, págs. 55 y ss.).

34 Klein, H.: Parties..., págs. 58-63. 
ción. ${ }^{35}$ Creo que debe señalarse la incorporación a la política de sectores que ni siquiera existían al iniciarse la hegemonía liberal, destacándose la capacidad republicana para movilizar las capas de artesanos que, según declaraciones de los propios dirigentes del Partido Republicano habían pasado a ser los sectores más seguros de la militancia. Junto a ello, cabe pensar en la escisión de sectores dominantes, a causa de la política financiera de Montes, así como los problemas de integración de capas de profesionales desvinculados de la red de clientela del Partido Liberal, obligado a reajustes del gasto burocrático en la depresión de 1919. En cualquier caso, se trataba del triunfo de una opción ambigua, cuya consistencia habría de desbaratarse al contacto con la gestión pública.

La primera presidencia del Partido Republicano habría de encargarse a Bautista Saavedra, que había manejado los hilos de la conspiración de 1920, disponiendo de una base partidaria potente en la capital. Los esfuerzos de los sectores más conservadores del Partido Republicano para imponer la candidatura de Daniel Salamanca resultaron inútiles, y el sector derechista acabó retirándose del parlamento y del partido para constituir el nuevo Partido Republicano Genuino. Habría que esperar veinticinco años de profundas convulsiones sociopolíticas para que el republicanismo vol-

35 Klein afirma que la crisis sacudió al país en 1920-1921, cuando las cifras nos indican algo distinto. Las tasas a la exportación del estaño, que habían supuesto 1.949 .000 bs. en 1914, fueron creciendo hasta alcanzar 7.381.000 en 1918. Tras una caída en 1919, que bajó los ingresos estatales hasta 5.951.000, se inició la recuperación en 1920, llegándose a los 6.208.000 en 1920. Dado que las tasas no variaron en lo que a derechos sobre la exportación se refiere, tal crecimiento sólo puede explicarse por el incremento de la producción (Peñaloza, Historia..., vol. II, 233-234). La cotización del estaño en el mercado mundial, tras haberse reducido drásticamente en 1914, fue recuperándose hasta doblar la cifra de este año en 1920. La caída de la cotización sólo se dio en 1921-1922. A la vista de estos datos, resulta algo forzado vincular la crisis con el golpe de estado de 1920.

36 Klein, H.: Parties..., pág. 65: "Saavedra tenía su base en los intereses comerciales y los de la creciente clase media de La Paz, su ciudad natal, a la que había representado largo tiempo en el Congreso."; Céspedes, A.: El dictador..., págs.. 71 y ss.;El más grave cargo que se hizo a Saavedra fue el de haberse hecho elegir por esos porotos, que no representaban sino a la chusma mestiza del republicanismo.”; Alvéstegui, D.: Salamanca..., vol. II, pág. 376: “ No vio el señor Montes (...) que un partido que tenía a la clase obrera por base de su acción poseía la verdadera fortaleza política. En cierto grado, Salamanca participó de este error (...). Saavedra (...) demostró tener mayor capacidad de percepción al valorar la significación del fenómeno social que llevaba consigo los hechos políticos de ese momento"; Díaz Machicao, P.: Saavedra..., págs. 88-89: El hombre saboteado por las élites apoyó la gravitación gubernamental en gentes de modestas apariencias."; T. Marof, prólogo a B. Carrasco: Siles..., pág. XIX: "El presidente se vio solo, casi abandonado de todos y en este instante recurre a un procedimiento eficaz: se rodea del pueblo, llama a los artesanos, combate a la aristocracia liberal oponiéndole la fuerza popular."; Lora, G.: Historia del movimiento obrero boliviano y vol. II, La Paz, 1968: "Las ramas republicanas, particularmente la que siguió a Bautista Saavedra, representaron la insurgencia de la clase media en la política". 
viera a unificarse. El triunfo de Saavedra y su influencia prolongada en la vida política boliviana procedía de su captación de los sectores populares, factor que han reconocido tanto sus contemporáneos como los ensayistas posteriores. ${ }^{36}$ En las condiciones de desarrollo en que se hallaba la clase obrera boliviana, no resultaba impensable mantenerla en los límites de la opción republicana a base de concesiones como las leyes sobre accidentes de trabajo y la jornada de ocho horas para algunos oficios. ${ }^{37}$

El talante relativamente conciliatorio del saavedrismo con el movimiento obrero no tuvo paralelo en el trato dispensado a los campesinos. Inmediatamente después de la revolución de 1920, se iniciaban en Achacachi fórmulas de resistencia comunitaria consistentes en el reforzamiento de una economía paralela a la de la hacienda. El programa republicano de 1915 afrontaba el "problema indígena" en términos paternalistas, fijándose las soluciones en el terreno de la educación. Los comentarios de la prensa más vinculada al partido reiteraron los prejuicios de blancos y mestizos capitalinos contra la presencia de los indígenas en la ciudad. ${ }^{38}$ Saavedra había mostrado públicamente su desagrado por la permanencia de las tierras de comunidad, utilizando frases durísimas en el proceso realizado contra dirigentes indígenas a comienzos de siglo. ${ }^{39}$ La matanza de Jesús

37 Aunque desde 1914 habían estallado algunos conflictos mineros de importancia — singularmente el de Catavi en 1919, con intervención del Ejército_-, la clase trabajadora se hallaba en un nivel muy incipiente de organización, sin haber superado en algunos casos los esquemas gremiales. Todavía en la segunda década del siglo, los dirigentes de la Federación Obrera de La Paz militaban en el Partido Liberal, haciendo presidente honorario de la sociedad a Ismael Montes. En 1912 se escindiría la Federación Obrera Internacional, que seis años más tarde tomaría el nombre de Federación Obrera del Trabajo. La influencia decisiva correspondió a la corriente anarcosindicalista o bien simplemente sindicalista. Sin embargo, a través de la FOT, y con el impulso especial del Centro de Estudios Sociales de La Paz, se constituyeron organizaciones socialistas locales que habrían de confluir en un primer Partido Socialista a escala nacional, llegando a enviar al parlamento diputados como Perales o Soruco. En 1922 estalló una huelga general ante la que Saavedra hubo de ceder, reconociendo la personalidad jurídica de la Federación Ferroviaria y retirando un proyecto de limitación de huelgas. La masacre de las mina de Uncía, en 1923, selló el distanciamiento entre movimiento obrero y saavedrismo. En 1925, justamente cuando concluía el mandato del líder republicano, se celebraba un Congreso creador de la Confederación Nacional del Trabajo. Lora, G.: Historia..., vols. II y III; Barcelli, A.: Medio siglo de luchas sindicales revolucionarias en Bolivia. La Paz, 1956; Barrios Vila, E.: Historia sindical de Bolivia. Oruro, 1966.

38 El diario La Razón señalaba en 1930: “...esa inútil aglomeración de indios en la plaza Murillo, por ejemplo, ya sea sentados en cuclillas, en posturas un tanto simiescas, en las aceras del palacio legislativo o en las escalinatas del monumento a Murillo; el aspecto de nuestra plaza principal adquiere contornos de aldea africana.” Barnadas, J. M.: Apuntes para una historia aymara, La Paz, 1975, pág. 71.

39 Barcelli, A.: Medio siglo..., pág. 101, recoge sus comentarios sobre "orangutanes sanguinarios" y "raza atrofiada moralmente". El contexto ideológico de esta postura ha sido perfectamente reflejado por M.D. Démelas en "Darwinismo a la criolla. El darwinismo social en Bolivia, 1880-1910." Historia Boliviana, 1/2, Cochabamba, 1981, págs. 55-82. 
de Machaca habría de mostrar cuál era la línea de integración y reforma social que estaba dispuesto a tolerar el republicanismo. ${ }^{40}$

Lo que me interesa, fundamentalmente, es indicar el grado de coherencia que existe entre la gestión liberal y la republicana, así como el carácter de mero recambio de élite que supone la "revolución" de 1920. De hecho, el primer gobierno republicano fue muy generoso con la penetración extranjera, particularmente la estadounidense, en pleno proceso de sustitución del capitalismo británico en amplias áreas de América Latina. ${ }^{41}$ En la etapa inmediata a la Gran Guerra, la orientación del comercio exterior boliviano sufrió un giro importante, en beneficio de los Estados Unidos. ${ }^{42}$ De las observaciones de Marsh se desprende, sin embargo, que el capital estadounidense no penetró a través de la minería del estaño, sino de los préstamos y el petróleo. Estos son los dos aspectos de la política saavedrista que más inciden en el futuro económico del país, y los que mejor nos pueden dar la imagen de tratamiento de los intereses nacionales por parte del republicanismo populista.

El gobierno de Saavedra tuvo que enfrentarse con la depresión de la posguerra que, al afectar a la cotización mundial del estaño, rebajó considerablemente los ingresos estatales entre 1921 y 1923 , fecha en que se alteró el sistema impositivo. ${ }^{43} \mathrm{Al}$ problema de la depresión se añadía el de la deuda heredada de los gobiernos liberales. Para redimirla e iniciar una política de obras públicas que prestigiara al gobierno, se contrató el

40 Choque, R.: "Sublevación y masacre de los comunarios de Jesús de Machaca". Antropología, n. ${ }^{\circ}$ 1, La Paz, 1978. Rivera, S.: Oprimidos pero no vencidos. La Paz, 1984, pág. 51.

41 "Las inversiones de capital de ciudadanos de Estados Unidos en Bolivia ascienden, aproximadamente, a \$ 100.000.000: unos 40 millones en obligaciones del Estado y el resto en la explotación de minas y petróleos". (Marsh, Nuestros banqueros..., pág. 20). "No hay en el mundo un país en el que las leyes mineras sean más favorables a los extranjeros que en Bolivia" (palabras del cónsul Hazeltine recogidas por W. Schurz en Bolivia..., pág. 107).

42 En 1913, las importaciones procedentes de los Estados Unidos representaban un 7,38\% del total, mientras que las británicas llegaban al 20,27\%. En 1918, las compras a Estados Unidos suponían un $32,31 \%$ frente al 11,85 dedicado a los productos británicos. Las exportaciones bolivianas a Estados Unidos no llegaban al 1\% en 1913, frente al 80,85\% que recibía Gran Bretaña. Cinco años más tarde, los Estados Unidos absorbían el 49,85\%, quedando Gran Bretaña en un 41,61\%. Schurz, W.: Bolivia..., págs. 224-228.

43 Los ingresos totales del Estado, que sumaban 30 millones de bolivianos en 1920, bajaron a 23,7 millones en 1921 y a 22,9 al año siguiente. Los gastos fueron, respectivamente, $31,8,31$ y 36,4 millones. Aunque el volumen del estaño exportado aumentó, la baja en la cotización hizo que el valor pasara de 7,7 millones de libras esterlinas a 4,9. En este marco hay que situar la agitación obrera de los primeros años del republicanismo y la reforma fiscal de 1923, que supuso un gravamen proporcional a los beneficios y el aumento de las tasas a la exportación. Los ingresos del Estado se incrementaron, así, en 1924 y 1925 a 30 y 43 millones de bolivianos respectivamente, resultando 1924 uno de los escasísimos años en los que los ingresos superaron a los gastos. CEPAL: El desarrollo..., págs. 7 y 11. 
empréstito Nicolaus, probablemente el más célebre y oneroso en la historia boliviana junto con el firmado por Montes con Speyer and Co. El empréstito con la Stiffel Nicolaus, Equitable Trust Company y Spencer Trask Company se elevaba a 33 millones de dólares, emitiendo el Estado obligaciones al $8 \%$ con vencimiento en 1947, sin posibilidad de ser redimidas antes de 1937. Bolivia garantizaba la emisión con prácticamente todas sus rentas. Se formaba una Comisión Fiscal Permanente, integrada por tres miembros - dos de ellos a propuesta de los banqueros- para observar el cumplimiento de las garantías. Según ha calculado M. Marsh, un $46 \%$ de la renta nacional de 1925 estaba dedicada a la atención de la deuda pública. En ese mismo momento, para escapar al peso de la fiscalidad boliviana, Simón I. Patiño formaba la Patiño Mines and Enterprises Consolidated. Su participación en el total de las exportaciones del estaño boliviano en 1918 era del 60\%.44

Las primeras exploraciones petrolíferas en el Oriente boliviano habían comenzado en los años finales del siglo XIX, pero la constitución de la más antigua empresa de importancia data de 1912, cuando Lavadenz organizó el Sindicato de Oriente Boliviano, en colaboración con la Casa Percival Farqhar. El hundimiento de ésta llevó a la alianza del capital boliviano con el chileno, tras negociaciones fracasadas con la Royal Dutch Shell. A pesar de la quiebra de empresas bolivianas como Aguila Doble o chilenas como Calacoto, las concesiones continuaron, y cuando el presidente Montes prohibió nuevos permisos, en 1916, se habían entregado 3 millones de hectáreas. El gobierno Gutiérrez Guerra firmó un contrato con la empresa Richmond, Levering and Co., de Nueva York, en febrero de 1920. Tal contrato permitía a la Richmond Levering la exploración de 3 millones de Hás., concediéndosele un millón por un período de cincuenta años. El Estado se reservaba el $15 \%$ del producto bruto y dejaba exclusivamente para las instituciones bolivianas cualquier decisión expropiatoria en caso de incumplimiento de contrato. En 1920, la Standard Oil entabló contactos con las concesionarias estadounidenses en Bolivia, para la transferencia de sus zonas de exploración. Al año siguiente, se constituyó la Standard Oil of Bolivia, que para 1926 se había apropiado de unos siete millones de Has. y se desenvolvía en situación de práctico monopolio. En 1921, antes de firmar la aceptación de las transferencias, el Congreso aprobó una Ley

44 Marsh, M. A.: Nuestros banqueros..., pág. 21. Para la formación y crecimiento de la empresa Patiño, ver Klein, H. S.: "La formación del imperio del estaño de Patiño". Historia Boliviana, 3/1, Cochabamba, 1983, págs. 237-252. 
Orgánica destinada a controlar las concesiones, en la que se estipulaba que éstas no tendrían más de 100.000 Has. y el Estado se aseguraba un $11 \%$ de la producción bruta, más un impuesto progresivo sobre los beneficios. El contrato firmado con la Standard Oil en 1922 señalaba, además, que se deberían comenzar los trabajos de perforación en un plazo de diez meses; que, de no hacerlo, los propietarios pagarían una multa de 50.000 dólares, y que la concesión caducaría a los 24 meses si en este período no se hubieran realizado tales trabajos. La situación de la Standard resultaba totalmente anómala: por un lado, el origen de su concesión estaba en la transferencia de los derechos obtenidos por otras empresas; pero el contrato con el Estado había sido firmado en 1922, una vez aprobada la ley que fijaba la extensión máxima muy por debajo de lo adquirido por la Standard a las anteriores empresas. La postura confesa de Saavedra, sin embargo, era el reconocimiento de que Bolivia no disponía de un capital alternativo al de la Standard, y así lo manifestó en su mensaje presidencial de $1924 .{ }^{45}$

\section{El advenimiento de la crisis}

Si Saavedra ha pasado a la historia oficial del republicanismo como el líder capaz de enlazar con las capas populares de la ciudad, tiñendo de legislación social un proyecto en el fondo continuista, su sucesor, Hernando Siles Reyes (1925-1930) se presentó como el impulsor de la "generación del Centenario", tratando de formar y consolidar una fuerza política que rompiera con el esquema de los partidos tradicionales. ${ }^{46}$ En busca de una base para este proyecto, que incluía la constitución de su propia clientela, Siles se acercó a una juventud universitaria y profesional sensible a algunas de las corrientes ideológicas renovadoras que recorrían el continente, en especial el nacionalismo populista. En los momentos previos a la descomposición del orden liberal, justamente antes de la crisis de 1929 y del desastre del Chaco, apuntaba ya una posición política ambigua, definida tan sólo en términos generacionales, ataviada de un nacionalismo

45 La información sobre este punto está basada en los siguientes trabajos: Almaraz, S.: Petróleo en Bolivia. La Paz, 1958; Montenegro, C.: Frente al derecho del Estado, el oro de la Standard Oil. La Paz, 1938; Klein, H. S.: "American Oil Companies in Latin America. The Bolivian Experience", Inter American Economic Affairs, XVIII, 2, Washington, 1964, págs. 47-72; Alcázar, M.: Abel Iturralde, el centinela del petróleo. La Paz, 1944.

46 La mejor biografía de este presidente es la de Alfonso Crespo Rodas: Hernando Siles. El poder y la angustia. La Paz, 1986. 
antioligárquico, aunque no anticapitalista, entendiendo el "socialismo" como la intervención de un Estado fuerte en favor de las clases populares, y depositando sus esperanzas en una nebulosa burguesía nacional, élite que habría de romper las relaciones de dependencia neocolonial mediante la reinversión de sus beneficios en el desarrollo integrado de Bolivia. ${ }^{47}$

Siles, que ya había tomado contacto con sectores juveniles opuestos a la demagogia de la Cruzada Pro-Indio de 1926, constituyó el Partido Nacionalista en 1927. Frente a la línea de los jóvenes radicales, como Céspedes y Montenegro, se eligió a núcleos menos agresivos, dispuestos a aceptar un proyecto que se limitaba a retocar muy superficialmente las estructuras sociopolíticas del país, a pesar de un lenguaje resueltamente antitradicional. ${ }^{48}$ Tal programa resultaba especialmente moderado en comparación con las propuestas que se estaban realizando en la Universidad, al calor del movimiento de reforma iniciado en Córdoba. La I Convención de Estudiantes, de la que surgiría la Federación Universitaria Boliviana en 1928, aprobó un programa mucho más radical, que incluía la reforma agraria, la socialización progresiva de la riqueza y la lucha contra el imperialismo norteamericano. ${ }^{49}$

El nacimiento de esta nueva fuerza social, que se sumaba al emergente sindicalismo obrero, no tenía cabida en el proyecto político de Siles que, sin embargo, se aisló también, con sus propuestas formalmente antitradicionalistas, de una posible alianza con los liberales y los republicanos. Dicho aislamiento coincidía con los primeros signos de la crisis del 29, especialmente agudizados por el grave desequilibrio presupuestario heredado de las administraciones anteriores. El montante de la deuda pública fue creciendo, de 127 millones en 1924 a 193 millones en 1928. Antes de la firma del empréstito Dillon and Read de este año, la amortización de la

47 En sus memorias, Augusto Céspedes, uno de los intelectuales clave en esta generación, asî como en la del Chaco, ha dejado un estimulante examen de la cultura de la época: "Nos atraía la fraseología del APRA y los relámpagos de la revolución mejicana. Leíamos los discursos de Obregón y de Calles y la lírica premonitoria de la 'Raza Cósmica' (...). Despertamos al anuncio de que cada generación poseía un destino (...). Empezamos a cumplir el ideario de romper con el pasado próximo, llenando de improperios a los conductores de los partidos tradicionales." Céspedes, A.: El dictador..., págs. 82-83.

48 El Manifiesto de la nueva agrupación señalaba, en su programa mínimo, la modificación de las leyes electorales, el presupuesto quinquenal, revisión de las leyes sociales en favor de la mujer, el obrero y el niño, la revisión del sistema tributario, y un Departamento administrativo que se encargara del indio. Véase Díaz Machicao, P.: Historia de Bolivia. Guzmán, Siles, Blanco Galindo, 1925-1931. La Paz, 1955, págs. 59 y ss.

49 Gumucio, M. Baptista: Revolución y Universidad en Bolivia. La Paz, 1956, págs. 50 y ss. Klein, H.: Parties...,págs. 99 y ss. 
deuda suponía la mitad de las rentas del Estado..$^{50} \mathrm{El}$ déficit de la Hacienda pasó de un 3,3\% en 1925 a un 25,1 en 1930, rebajándose en este año los ingresos a la cifra más baja desde 1924. Solamente el recorte de los gastos en 11 millones de bolivianos con respecto a 1929 impidió que el déficit resultara catastrófico. Las exportaciones de estaño alcanzaron el mayor volumen de su historia en 1929, pero tal aumento de la producción no hacía sino tratar de compensar la caída en el precio que venía observándose desde 1927 y que alcanzaría su nivel más bajo en 1932. En función de una caída en los ingresos fiscales por beneficios empresariales, la recaudación del Estado se redujo en mayor proporción que el valor de las exportaciones. ${ }^{51}$ En el momento de apuntar la crisis, el presidente requirió el consejo de una comisión de expertos dirigida por el profesor Walter Kemmerer. La simple enumeración de los proyectos de la comisión nos ofrecen una idea del desorden en que se hallaban las finanzas bolivianas. ${ }^{52}$ Para agravar este desorden, Siles recurrió a nuevos empréstitos foráneos, por un total de 37 millones de dólares, en su mayor parte orientados a la satisfacción de las deudas pendientes. ${ }^{53}$ Por otro lado, la caída en la cotización del estaño supuso la exigencia de mayores concesiones del Estado a la minería, ya fuera en la intervención en el costo de los fletes, ya fuera en asegurar el control de la paz social en caso de despidos masivos. ${ }^{54}$

Las penosas condiciones del mercado externo y su repercusión en los ingresos fiscales habían de entorpecer decisivamente la capacidad gubernamental para dotarse de una base alternativa a las de las viejas clientelas liberal-republicanas. Por el contrario, el proyecto regeneracionista de Hernando Siles acabó enfrentándose a su teórica base social, la juventud

50 Siles, H.: Mensaje del presidente constitucional de la República de Bolivia al Honorable Congreso Nacional de 1929. La Paz, 1930, pág. 36.

51 CEPAL: El desarrollo..., págs. 11-12.

52 La Comisión indicaba la necesidad de reforma monetaria, con exacta fijación del valor-oro; ley general de bancos acompañada de la conversión del Banco de la Nación Boliviana en un Banco Central; nuevo sistema de cargas fiscales sobre la propiedad inmueble, dispersa en rentas departamentales y carente de una evaluación adecuada de la base imponible; reforma del impuesto sobre la renta; ley orgánica del presupuesto que impidiese la aprobación de gastos extraordinarios por parte del Congreso, en contra de las previsiones del poder ejecutivo; creación de una Controlaría General para fiscalizar los gastos públicos. Mendoza, F.: La misión Kemmerer en Bolivia. La Paz, 1927. Salvo la propuesta de creación de un Banco Central, las medidas fueron obviadas.

53 Peñaloza, L.: Historia..., vol. II, págs. 446 y ss. El mejor estudio sobre los efectos de la crisis del 29 en Bolivia es el de Whitehead, L.: "La grande crisi in Bolivia", Studi Storici, XIII, 3, Bolonia, 1972, págs. 517-550.

54 Sobre las exigencias del conjunto de la minería, véase Lofstrom, W. L.: Attitudes of an Industrial Pressure Group in Latin America. The Asociación de Industriales Mineros de Bolivia, 1925-1931. Ithaca, 1968, págs. 61 y ss. 
universitaria, temerosa de que el presidente tratara de implantar un régimen dictatorial. El presunto "caudillo" de la juventud acabaría siendo derribado por un golpe combinado de civiles y militares que, tras un breve interludio de gobierno de las Fuerzas Armadas, celebraría elecciones, ganadas con facilidad por el tándem genuino-liberal de Daniel Salamanca y José Luis Tejada Sorzano a comienzos de 1931.

Este reencuentro de los partidos tradicionales en una candidatura conjunta había de darse, sin embargo, en pésimas condiciones para la supervivencia del viejo orden. En 1930, la deuda había rebasado los 200 millones de bolivianos. Al año siguiente, siguiendo el ejemplo de diversos países del área, se declaraba la suspensión del pago de la deuda externa, recurriendo a un empréstito interior financiado por el Banco Central y el Banco Mercantil..$^{55}$ El precio del estaño continuaba descendiendo y, con él, los ingresos del Estado. Para compensar el exceso de stock, se creó el Comité Internacional del Estaño, destinado a asegurar la recuperación de su valor, asignando a los diversos países productores una cuota fija de exportación. ${ }^{56}$ Sin duda, ello podría haber resuelto las desventajas de la caída del precio, pero en modo alguno remontaba la precaria situación de la hacienda pública y de las necesidades de divisas para el abastecimiento del mercado interno. Además, la asignación de cupos había de convertirse en una constante fuente de enfrentamientos, primero entre la mediana y la gran minería, y posteriormente entre los tres grandes productores, Patiño, Hochschild y Aramayo. ${ }^{57}$

En un primer momento, Salamanca se inclinó por una política de austeridad, restringiendo el gasto público. A partir de 1932, se lanzaría a una política inflacionaria, incrementando la emisión de billetes a pesar de las advertencias expresadas por el Directorio del Banco Central. ${ }^{58}$ Dicha política inflacionaria, pensada en principio para cubrir los empréstitos estata-

55 Banco Central de Bolivia: Tercera memoria anual, correspondiente a la gestión de 1931. La Paz, 1932, págs. 16-17.

56 El trabajo clásico sobre este tema es el de K. Knorr: Tin under control. Stanford, 1945. Para la gestión del ITC en Bolivia, véanse Hallowell, B.: "Administration of Tin Control in Bolivia, 1931-1939", Inter American Economic Affairs, 3, Washington, 1949, págs. 3-24; Hillman, J.: "Bolivia and International Tin Control”, Journal of Latin American Studies, 20, Cambridge, 1988, págs. 83-110.

57 Lofstrom, W. L.: Attitudes..., págs. 65 y ss; para la agudización de los enfrentamientos entre los tres grandes unos años después, véase Gallego, F.: Ejército, nacionalismo y reformismo en América Latina. La gestión de Germán Busch en Bolivia, 1917-1939. Barcelona, 1992, págs. 111 y ss.

58 El total de billetes —en circulación y en depósitos- pasó de un valor de 37 millones de bolivianos en 1931 a los 80 millones en 1932. Banco Central de Bolivia: Sexta memoria anual, correspondiente a la gestión de 1934. La Paz, 1935, pág. 59. 
les, se dedicó a la financiación de gastos militares. La debilidad política de la coalición liberal-genuina quiso obviarse mediante el recurso a un episodio de política exterior que, al tiempo que distraía las tensiones emergentes por la depresión, era capaz de rodear de prestigio al gobierno, silenciando cualquier oposición. Por otro lado, el enemigo a batir parecía accesible y en el territorio del Chaco se preveía la existencia de inmensos recursos petroleros. Siendo uno más de los numerosos conflictos de frontera padecidos por el continente desde la independencia, la guerra entre Bolivia y Paraguay habría de ser la de mayor intensidad y duración entre dos países americanos en el siglo XX. Y su función, en lugar de reforzar el orden tradicional de ambos países, sería la de sellar la crisis definitiva de un modelo de crecimiento que sólo en apariencia era estable y que sólo en los sueños de cierta historiografía revisionista parece plantearse como el camino a seguir. 